\title{
Chapter
}

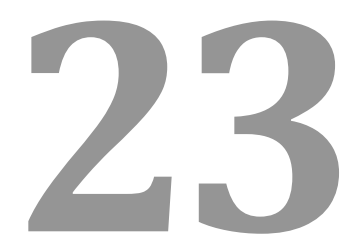

\section{NANOMEDICAL APPLICATIONS OF GRAPHENE AND GRAPHENE OXIDE}

Malgorzata Aleksandrzak*, Karolina Urbas, Magdalena Onyszko, and Ewa Mijowska

West Pomeranian University of Technology, Szczecin, Department of Nanotechnology, Piastow 45 70-311 Szczecin, Poland 


\section{Contents}

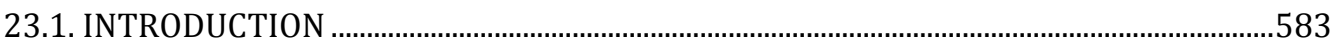

23.2. BIOCOMPATIBILITY OF GRAPHENE AND GRAPHENE OXIDE ……................................585

23.3. GRAPHENE AND GRAPHENE OXIDE IN TARGETED DRUG DELIVERY .........................594

23.4. GRAPHENE AND GRAPHENE OXIDE IN PHOTODYNAMIC AND

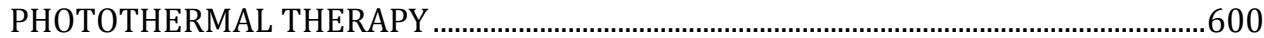

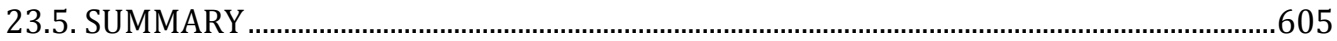

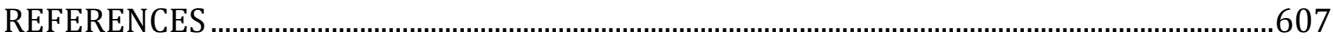




\subsection{INTRODUCTION}

Typical carbon based nanomaterials such as graphene and its derivatives, fullerene and carbon nanotubes, possess many interesting physical and chemical properties that are useful in biomedical and biological applications [1-3]. As a result, graphene-based materials have attracted considerable attention in the past few years. Graphene and graphene oxide (GO) have been extensively explored as promising biomaterials for biomedical applications due to their unique properties: two-dimensional planar structure, large surface area, chemical and mechanical stability and good conductivity. Since its discovery in 2004, graphene, a single-atom thick and a two dimensional arrangement of conjugated $\mathrm{sp}^{2}$ carbons in a honeycomb structure, has been studied extensively in the biotechnology field owing to its multivalent functionalization and efficient surface loading with various biomolecules. A high surface area-to-volume ratio and excellent chemical versatility make this special material an ideal candidate for the development of a new generation of nanomedicines with applications encompassing the detection of biomarkers to imaging and cancer therapy. GO, which is highly oxidized graphene with number of carboxyl, hydroxyl and epoxide groups on its surface and edges, can load various drug molecules via $\pi-\pi$ stacking, hydrophobic or electrostatic interactions and hydrogen bonding. GO can be easily functionalized with various hydrophilic macromolecules which can improve its biocompatibility and regulate its properties in biological systems or with targeting ligands or active agents for selective or controlled drug delivery.

Graphene sheets were first separated from graphite in a process of mechanical exfoliation of graphite by using adhesive tape. Using this process, single-layer graphene may be obtained. However, this approach yields only small quantities of graphene that are useful only for fundamental study. Subsequently, large-area graphene films composed of a single or few layers have been produced by chemical vapor deposition (CVD) on metal substrates. This method is accomplished by capturing a hydrocarbon precursor via surface chemical adsorption by catalytic decomposition of hydrocarbons on transition metals such as $\mathrm{Pt}, \mathrm{Ni}, \mathrm{Ru}, \mathrm{Rh}, \mathrm{Ir}$ or $\mathrm{Cu}$ [8]. Another method to obtain graphene sheets is the growth of graphitic layers by the sublimation of Si from $\mathrm{SiC}$ substrates. This approach has been known since 1975, when Bommel et al. first reported graphite formation on the (0001) polar plane of SiC [9]. In 2007, de Heer et al. reported the fabrication of an epitaxial graphene down to one or two layers on the (0001) face of a $6 \mathrm{H}-\mathrm{SiC}$ wafer using a thermal decomposition method [10]. Although epitaxial graphene and CVD-grown graphene are highquality materials, transfer to another substrate is necessary, which limits the versatility of these processes in a wide range of applications. The last method of graphene synthesis is the creation of a colloidal suspension made of graphite and its derivatives. So far, oxidative exfoliation via the Hummers method is the 
most popular method for the generation of GO [11]. It involves oxidative exfoliation of graphite using a mixture of strong oxidants. The prepared GO, with a large number of functional groups on its surface, can be further reduced to obtain reduced graphene oxide (RGO) by reacting with reducing agents such as $\mathrm{N}_{2} \mathrm{H}_{4}$ [12]. Graphene oxide can be also produced by the Brodie [13] and Staudenmaier [14] methods, which require the utilization of strong oxidants. The level of the oxidation can be varied depending on reaction conditions and the type of graphite precursor. This chemical approach is scalable, enables high-volume production of graphene or GO that can be easily chemically functionalized and used for a wide range of applications. The most common methods of graphene production are presented in Figure 1.

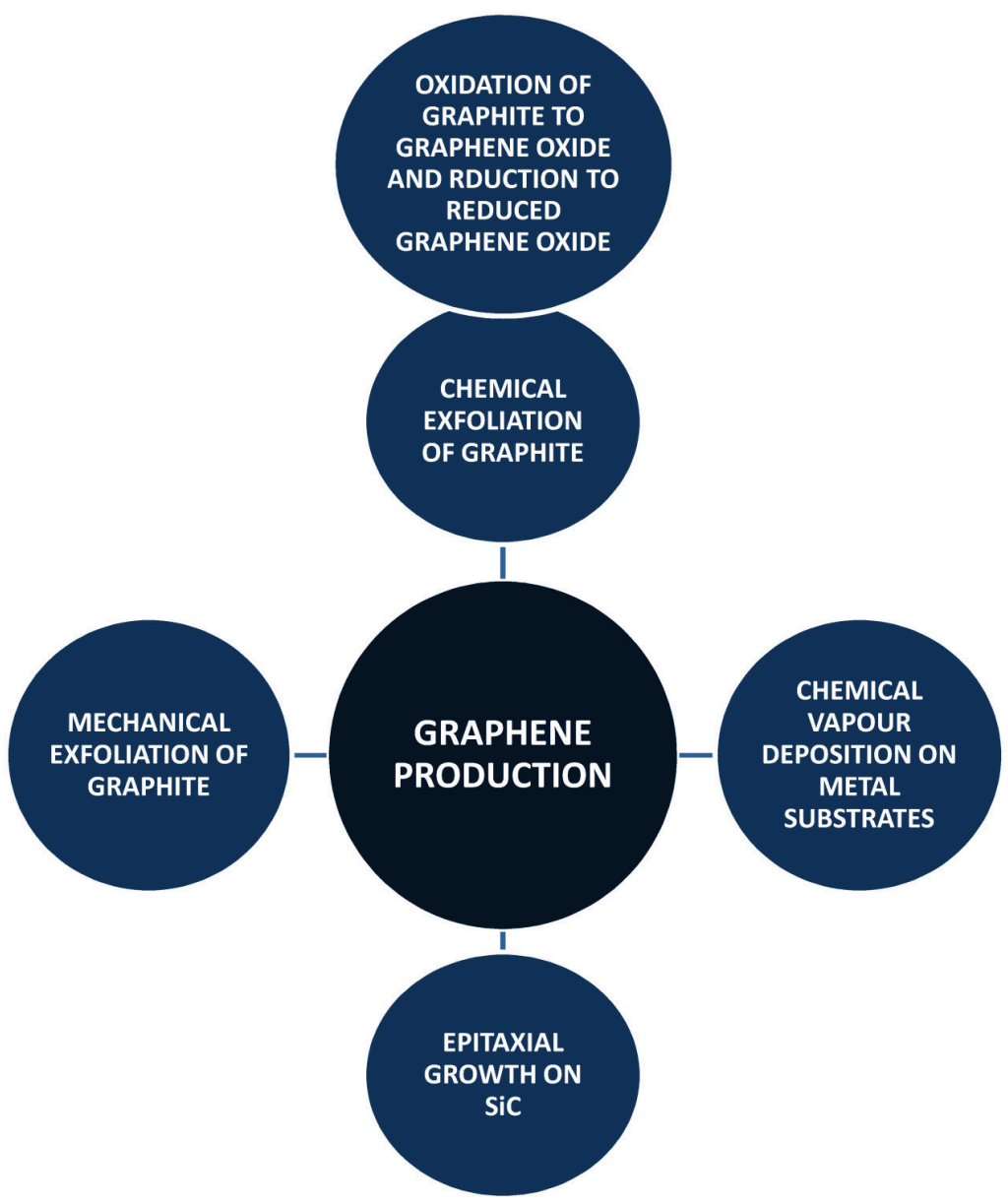

Figure 1. Schematic representation of common methods used for graphene production 


\subsection{BIOCOMPATIBILITY OF GRAPHENE AND GRAPHENE OXIDE}

In order to use graphene and GO in clinical applications, it is necessary to verify their biocompatibility and toxicity by performing extensive in vitro and in vivo studies using cells and animal models. The first report on the interaction between GO and human dermal fibroblasts (HDF) was presented in 2011 by Wang et al. [15]. They examined fibroblasts cultured with different doses of GO for various periods of time (from 1-5 days) and showed that GO at a dose below $20 \mu \mathrm{g} \mathrm{mL}^{-1}$ was not toxic to the cells; however, a dose of more than $50 \mu \mathrm{g} \mathrm{mL} \mathrm{m}^{-1}$ led to obvious cytotoxicity and a decreased cell survival rate, observed as floating cells and apoptosis. This study showed that GO was internalized by cells and was mainly located inside the cytoplasm, as well as in lysosomes, mitochondria, and the endoplasm. Furthermore, as the culture time increased, the amount of GO inside the cells increased accordingly. GO appeared as black dots scattered throughout the cytoplasm and around the nucleus, although a few GO particles were located inside the nucleus. Next, the authors studied the effects of GO on cell adhesion proteins and found that cell adhesion decreased markedly with an increase in the GO concentration and culture time. HDF cells treated with GO at doses of $100 \mu \mathrm{g} \mathrm{mL}^{-1}$ and $20 \mu \mathrm{g} \mathrm{mL}-1$ exhibited morphological changes characteristic of apoptosis after $24 \mathrm{~h}$ and $72 \mathrm{~h}$, respectively, such as membrane vesicles, fragmentation, unclear cell boundaries and the formation of nodular structures encapsulating GO.

Chang et al. [16] also performed in vitro studies with GO. They examined the effects of GO on morphology, viability, mortality and membrane integrity of the lung cancer cell line A549. According to these studies, GO does not enter A549 cells and exerts no obvious cytotoxicity. However, it can cause dose-dependent oxidative stress in cells and induce a slight loss of cell viability at high concentrations $\left(200 \mu \mathrm{g} \mathrm{mL}^{-1}\right)$. They found that the size of GO was another factor that influenced A549 viability, since GO with a smaller particle size induced more viability loss than larger GO particles. Hu et al. [17] excluded oxidative stress as a reason for GO toxicity. They performed in vitro tests to assess the effect of fetal bovine serum (FBS) on the cytotoxicity of GO. They showed that, at low concentrations of FBS (1\%), human cells were sensitive to the presence of GO and showed concentration-dependent cytotoxicity. Interestingly, the cytotoxicity of GO was greatly mitigated at $10 \%$ FBS. Hence, the authors proposed that the cytotoxicity of GO nanosheets occurred as a result of physical damage to the cell membrane, which was induced by direct interactions between the cell membrane and GO nanosheets. This effect was largely attenuated when GO was incubated with FBS due to the high protein adsorption ability of GO. The cytotoxicity occurred mostly during the initial contact stage between GO and cells and was independent of exposure duration. As oxidative stress is a time-dependent process, it did not contribute to GO toxicity. 
Ruiz and co-authors [18] studied the role of GO films on mammalian cell (colorectal adenocarcinoma, HT-29) attachment and proliferation. They compared the attachment and growth of mammalian cells on glass slides coated with $10 \mu \mathrm{g}$ of GO to cells on uncoated glass slides. The results showed that the mammalian cells attached more efficiently to the GO-coated glass slides and grew, indicating that GO promotes cell attachment and proliferation.

Liao and co-workers [19] compared the cytocompatibility of GO with that of RGO using adherent skin fibroblasts. They found that RGO was more toxic to adherent cells than GO, probably due to faster sedimentation and the formation of more compact aggregates of graphene, as compared to GO, during $24 \mathrm{~h}$ of static aging; this greatly inhibited nutrient availability and the growth of human skin fibroblasts. Our group investigated the cytocompatibility of GO and RGO on mice fibroblasts (line L929) [20]. We examined the influence of the concentration of the nanomaterial and the dispersant used to stabilize the suspension (sodium deoxycholate (DOC), poly(ethylene glycol) (PEG) and the co-polymer Pluronic P123). The results showed that the dispersant used to stabilize the suspension, the type of material and its concentration significantly influenced cell toxicity. The highest viability of the cells was observed when both materials were dispersed in PEG. Both materials showed relatively good cytocompatibility when the concentration was between $3.125 \mu \mathrm{g} \mathrm{mL}^{-1}$ and $12.5 \mu \mathrm{g} \mathrm{mL}-1$. Increasing the concentration of the nanomaterial reduced the cell viability. A comparison of the cytocompatibility of GO and graphene was also performed by the Liao group [19]. They performed an in vitro study on the blood compatibility of GO and graphene particles of various sizes and oxygen content suspended in human red blood cells (RBCs) by assessing hemolysis. Both GO and graphene showed dose-dependent hemolytic activity on RBCs. In the case of GO, the extent of exfoliation and the particle size had critical effects on the degree of hemolysis. Smaller GO particles exhibited higher hemolytic activity than larger GO particles. Compared to individually dispersed GO sheets with a higher surface oxygen content, aggregated graphene showed lower hemolytic activity. The authors proposed that the disruption of the RBC membrane was attributed to the strong electrostatic interactions between negatively charged oxygen groups on GO and the graphene surface and positively charged phosphatidylcholine lipids, which are present on the RBC outer membrane. They also found that covering GO sheets with chitosan eliminated their hemolytic activity. A different method of graphene modification was investigated by Santos et al. [21] using poly(N-vinylcarbazole) (PVK); these authors showed that the obtained nanocomposite exhibited lower cytotoxicity compared to unmodified graphene. Cheng and co-workers [22] confirmed the high hemolytic activity of GO and proposed its reduction with dopamine and simultaneous adhesion to RGO by one-step pH-induced polymerization to polydopamine (pRGO) and further functionalization with heparin (Hep-g-pRGO) and protein (BSA-g-pRGO). They found that the obtained composites exhibited lower 
hemolysis ratios and no visible hemoglobin release was observed. After the reduction of GO and functionalization with a biopolymer, the amphiphilic structure of GO was destroyed, and the highly concentrated surface charge of GO vanished; thus, the resulting RGO had difficulty interacting with or partitioning into lipid bilayers, and hemolysis was greatly suppressed. Furthermore, the grafted biopolymer increased the electrostatic repulsion between RGO and the lipid bilayer of the red blood cell membrane, which might further inhibit strong cell interactions and suppress hemolysis. These authors further examined the morphology of human umbilical vein endothelial cells (HUVECs) cultured with the as-prepared composites or with GO reduced with hydrazine. Figure 2 presents the morphology of the cells analyzed by scanning electron microscopy. The best morphology was observed for the cells exposed to Hep-g-pRGO while hydrazine-RGO exhibited the highest toxicity. The cells treated with hydrazine-RGO could hardly attach onto the substrate and showed very few plasmodesma. Furthermore, some RGO particles were adhered to the cells, which might have caused serious adverse effects on the viability of the cells.
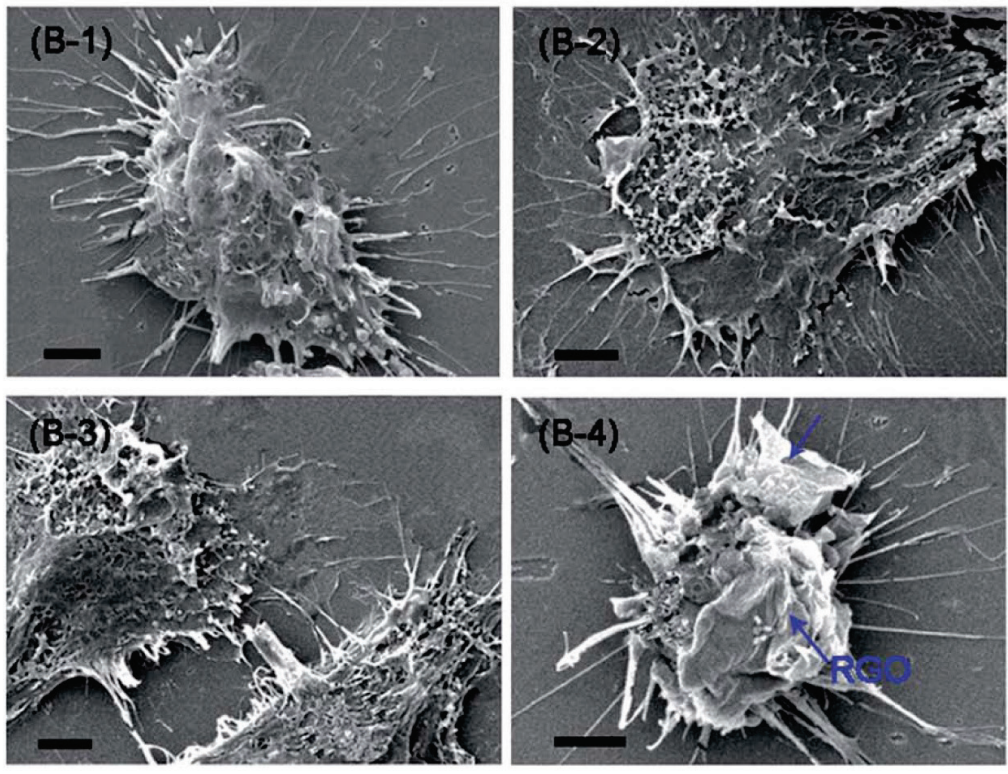

Figure 2. Scanning electron microscopy images of HUVECs cultured with pRGO (B-1), Hep-g-pRGO (B-2), BSA-g-pRGO (B-3) and hydrazine-RGO (B-4) at a concentration of $100 \mathrm{mg} \mathrm{mL}^{-1}$ for $24 \mathrm{~h}$ on glass supports. The black scale bar represents $2 \mu \mathrm{m}$ [22].

Singh et al. [23] examined the effect of amine modification of graphene on platelet reactivity. They revealed that amine-modified graphene had no 
stimulatory effect on human platelets, nor did it induce pulmonary thromboembolism in mice following intravenous administration. Moreover, it did not evoke the lysis of erythrocytes. These results differ remarkably from other observations with GO and RGO. They suggested that these effects arose from profound physical interactions between GO sheets and platelets. GO, which exhibits substantial interaction with cells, elicited activation-specific platelet responses including aggregation, a rise in intracellular calcium / reactive oxygen species and enhanced protein tyrosine phosphorylation, associated with extensive pulmonary thromboembolism. In contrast, $\mathrm{NH}_{2}$-modified graphene was inert toward cells, did not induce platelet stimulation, and had no demonstrable thrombogenicity in vivo. Negatively charged graphene sheets physically interacted with platelets and activated them, while positively charged sheets did not. As a direct interaction between nanomaterials and cells modulates critical cell signaling pathways and contributes to observed toxicity, the modification of surface charge with the ensuing diminished effect on nanomaterial cell interaction can bring about a significant attenuation in toxicity. Another method for enhancing GO biocompatibility is functionalization with nanoparticles. In our previous study [24], we showed that GO modification with magnetite nanoparticles resulted in improved biocompatibility with mouse fibroblasts (L929) compared to unmodified GO. A summary of these in vitro studies is presented in Table 1.

Jiao et al. reported on a metabolomics approach to investigate metabolic responses in graphene treated HepG2 cells [25]. They found that increasing the graphene concentration resulted in a decrease in creatine, which is an intracellular energy intermediate that plays a key role in safeguarding cellular energy storage and transmission. In contrast, graphene up-regulated the $\mathrm{N}^{2}$-(D-1-carboxyethyl)-arginine metabolite. Arginine has been found to be involved in urea cycle, an important metabolic pathway in which toxic ammonia produced from amino acid metabolism is converted into urea. This study also showed that graphene caused protein unfolding or mis-folded protein accumulation, resulting in increased energy requirements for protein synthesis, which was consistent with arginine and proline metabolism.

In vivo studies have confirmed the dose-dependent toxicity of GO. Wang et al. [15] investigated the influence of GOs on mice and showed that GO at low $(0.1 \mathrm{mg})$ and moderate $(0.25 \mathrm{mg})$ doses did not exhibit obvious toxicity to mice; conversely, a high dose $(0.4 \mathrm{mg})$ induced chronic toxicity, as 4 out of 9 mice died due to lung granuloma formation. It was also shown that GO was mainly located in the lung, liver, spleen, and kidney, and was inefficiently cleared by the kidney. Zhang and co-authors [26] also studied the distribution and biocompatibility of GO in mice and showed that it was predominantly deposited in the lungs, where it was retained for a long period of time. Moreover, GO exhibited prolonged blood circulation and low uptake in the reticuloendothelial system (RES). When the mice were exposed to GO at a dose of $1 \mathrm{mg} \mathrm{kg}^{-1}$ for 14 days, no pathological changes were observed in the 
examined organs. However, when the dose was increased to $10 \mathrm{mg} \mathrm{kg}^{-1}$, the authors observed pathological changes, including inflammatory cell infiltration, pulmonary edema and granuloma formation in the lungs of mice.

Table 1. Review on in vitro studies performed with graphene oxide, graphene and their modified forms

\begin{tabular}{|c|c|c|c|}
\hline Ref. & Material & Cell line & Results \\
\hline $\begin{array}{l}\text { Wang et al. } \\
\text { [15] }\end{array}$ & GO & $\begin{array}{l}\text { Human fibroblasts } \\
\text { (HDF) }\end{array}$ & $\begin{array}{l}\text { Dose-dependent toxicity, } \\
\text { cytotoxic at a dose above } \\
50 \mu \mathrm{g} \mathrm{mL} \mathrm{m}^{-1} \text {; GO mainly } \\
\text { located inside cytoplasm } \\
\text { such as in lysosomes, } \\
\text { mitochondria and the } \\
\text { endoplasm. }\end{array}$ \\
\hline $\begin{array}{l}\text { Chang et al. } \\
\text { [16] }\end{array}$ & GO & $\begin{array}{c}\text { Human lung } \\
\text { cancer cells (A549) }\end{array}$ & 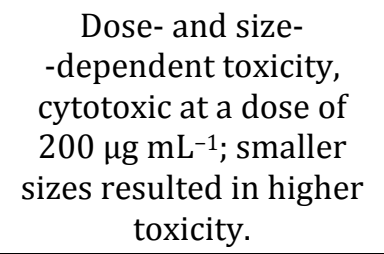 \\
\hline Hu et al. [17] & GO & $\begin{array}{c}\text { Human lung } \\
\text { cancer cells (A549) }\end{array}$ & $\begin{array}{l}\text { Concentration- } \\
\text { dependent toxicity; } \\
\text { cytotoxicity of GO as a } \\
\text { result of physical } \\
\text { damage to the cell } \\
\text { membrane, induced by } \\
\text { direct interactions } \\
\text { between the cell } \\
\text { membrane and GO } \\
\text { nanosheets; cytotoxicity } \\
\text { was independent of the } \\
\text { duration of exposure. }\end{array}$ \\
\hline Ruiz et al. [18] & GO & $\begin{array}{l}\text { Human colorectal } \\
\text { adenocarcinoma } \\
\text { cells (HT-29) }\end{array}$ & $\begin{array}{l}\text { Enhanced growth of } \\
\text { mammalian cells on } \\
\text { GO-coated glass slides, } \\
\text { indicating that GO } \\
\text { promotes cells } \\
\text { attachment and } \\
\text { proliferation. }\end{array}$ \\
\hline Liao et al. [19] & GO and RGO & $\begin{array}{l}\text { Adherent human } \\
\text { skin fibroblasts } \\
\text { (CRL-2522) }\end{array}$ & RGO more toxic than GO. \\
\hline $\begin{array}{l}\text { Wojtoniszak et } \\
\text { al. [20] }\end{array}$ & $\begin{array}{c}\text { GO and RGO } \\
\text { dispersed in PEG, } \\
\text { DOC and Pluronic }\end{array}$ & $\begin{array}{l}\text { Mouse fibroblasts } \\
\text { (L929) }\end{array}$ & $\begin{array}{c}\text { Dose- and dispersant- } \\
\text {-dependent cytotoxicity; } \\
\text { excellent }\end{array}$ \\
\hline
\end{tabular}




\begin{tabular}{|c|c|c|c|}
\hline Ref. & Material & Cell line & Results \\
\hline & & & $\begin{array}{c}\text { biocompatibility of } \\
\text { GO/PEG was observed. }\end{array}$ \\
\hline Liao et al. [19] & GO and graphene & $\begin{array}{l}\text { Human red blood } \\
\text { cells }\end{array}$ & $\begin{array}{l}\text { Dose and size-dependent } \\
\text { toxicity; GO with smaller } \\
\text { particles showed greater } \\
\text { hemolytic activity; } \\
\text { graphene showed better } \\
\text { biocompatibility than } \\
\text { GO; covering GO with } \\
\text { chitosan decreased its } \\
\text { toxicity. }\end{array}$ \\
\hline $\begin{array}{l}\text { Santos et al. } \\
\text { [21] }\end{array}$ & $\begin{array}{c}\text { Graphene } \\
\text { functionalized with } \\
\text { PVK }\end{array}$ & $\begin{array}{l}\text { Human fibroblasts } \\
\text { (NIH 3T3) }\end{array}$ & $\begin{array}{c}\text { The nanocomposite } \\
\text { exhibited lower } \\
\text { cytotoxicity compared to } \\
\text { unmodified graphene. }\end{array}$ \\
\hline $\begin{array}{l}\text { Cheng et al. } \\
\text { [22] }\end{array}$ & $\begin{array}{c}\text { GO reduced with } \\
\text { dopamine and } \\
\text { functionalized with } \\
\text { heparin }\end{array}$ & $\begin{array}{l}\text { Human blood cells } \\
\text { and human } \\
\text { umbilical vein } \\
\text { endothelial cells } \\
\end{array}$ & $\begin{array}{l}\text { Suppressed hemolysis } \\
\text { ratios and no visible } \\
\text { hemoglobin release. }\end{array}$ \\
\hline $\begin{array}{l}\text { Singh et al. } \\
\text { [23] }\end{array}$ & $\begin{array}{l}\text { Amine-modified } \\
\text { graphene }\end{array}$ & $\begin{array}{l}\text { Platelets from } \\
\text { human blood }\end{array}$ & $\begin{array}{l}\text { The material had no } \\
\text { stimulatory effect on } \\
\text { human platelets nor did } \\
\text { it induce pulmonary } \\
\text { thromboembolism, or } \\
\text { the lysis of erythrocytes. }\end{array}$ \\
\hline $\begin{array}{l}\text { Urbas et al. } \\
\qquad[24]\end{array}$ & $\mathrm{GO} / \mathrm{Fe}_{3} \mathrm{O}_{4}$ & $\begin{array}{l}\text { Mouse fibroblasts } \\
\text { (L929) }\end{array}$ & $\begin{array}{c}\mathrm{GO} \text { modification with } \\
\mathrm{Fe}_{3} \mathrm{O}_{4} \text { resulted in } \\
\text { enhanced } \\
\text { cytocompatibility. }\end{array}$ \\
\hline
\end{tabular}

In vivo studies confirmed the improved biocompatibility of GO following modification of its surface. For instance, Duch et al. [27] administered solutions of aggregated graphene, Pluronic dispersed graphene and GO directly into the lungs of mice and investigated the toxicity of these nanomaterials. The introduction of GO resulted in severe lung injury that persisted for more than 21 days after administration. In cultured alveolar macrophages and epithelial cells, GO increased the generation of mitochondrial reactive oxygen species by participating in redox reactions with components of the mitochondrial electron transport chain, thus activating inflammatory and apoptotic pathways. In contrast, this toxicity was significantly reduced in the case of pristine graphene after liquid phase exfoliation and was further minimized when the unoxidized graphene was well-dispersed with the block copolymer Pluronic. The authors suggested that the covalent oxidation of graphene is a major contributor to its pulmonary toxicity and proposed that the dispersion 
of pristine graphene in Pluronic provides a method for safe handling and potential biomedical application. Yang et al. [28] studied the in vivo behavior and long-term toxicity of GO and PEGylated GO derivatives after oral and intraperitoneal (i.p.) injection. They showed that PEGylated GO derivatives after oral administration could not be adsorbed by organs and were rapidly excreted. In contrast, PEGylated GO derivatives could be engulfed by phagocytes in the RES system after i.p. administration, in a size- and surface coating-related manner. Despite the long-term retention of i.p. injected GO and PEGylated GO in the mouse body, no significant toxicity was noted. The authors did not observe the formation of granulomas in mice injected with a high doses of GO or PEGylated GO. These results suggest that the in vivo behaviors and toxicology of nanomaterials, including graphene, are closely associated with their surface coating, size and route of administration. Chong et al. [29] examined the in vitro and in vivo toxicity of graphene quantum dots (GQD) with sizes varying from $3-5 \mathrm{~nm}$. The material did not induce apoptosis or necrosis in HeLa cells at a concentration of $160 \mathrm{mg} \mathrm{mL}^{-1}$, and the degree of apoptosis was not related to the dose of GQD. PEGylated GQD labeled with Cy7 were intravenously or intraperitoneally injected into Balb/c mice bearing 4T1 murine breast cancer tumors. The authors found that the material preferentially accumulated in the kidneys and at tumor sites compared with the control group, and leaked from the kidneys very quickly. Furthermore, after the injection of GQD-PEG (20 mg kg-1) to mice every day for 14 days, the main organs did not display any clear differences with the control group. The researchers suggested that the very high biocompatibility of GQD originates from the small particle size and high oxygen content compared to the more widely used PEGylated GO. In a later study, Qu et al. [30] reported that the addition of a non-ionic surfactant, Tween 80 , to the GO suspension hindered $\mathrm{GO}$ accumulation in the lungs of treated mice; however, the Tween 80-modified GO tended to accumulate more in the liver compared to the pristine GO suspension. The reason for this difference presumably resides in the first filtration of GO by the lungs as the particles circulate in the blood. Subsequently, the remaining GO in the circulation might be cleared by the liver, leading to greater GO deposition in the liver when GO was suspended in PBS compared to when GO was suspended in Tween 80. Therefore, the accumulation of GO in the liver was likely subject to the dynamics of filtration by the lung. In the liver, most GO aggregates were localized within Küppfer cells (macrophages) and no GO was found in hepatocytes (Figure 3), which highlights the important role of mononuclear phagocytic system (MPS) in clearing GO from the circulation. Moreover, the authors did not find GO in the kidneys of mice given either type of GO, suggesting that GO aggregates and agglomerates were not able to penetrate the glomerular basement membrane when passing through the kidneys. This was probably attributable to the inability of larger particles, such as GO, to cross the basement membrane [30]. 


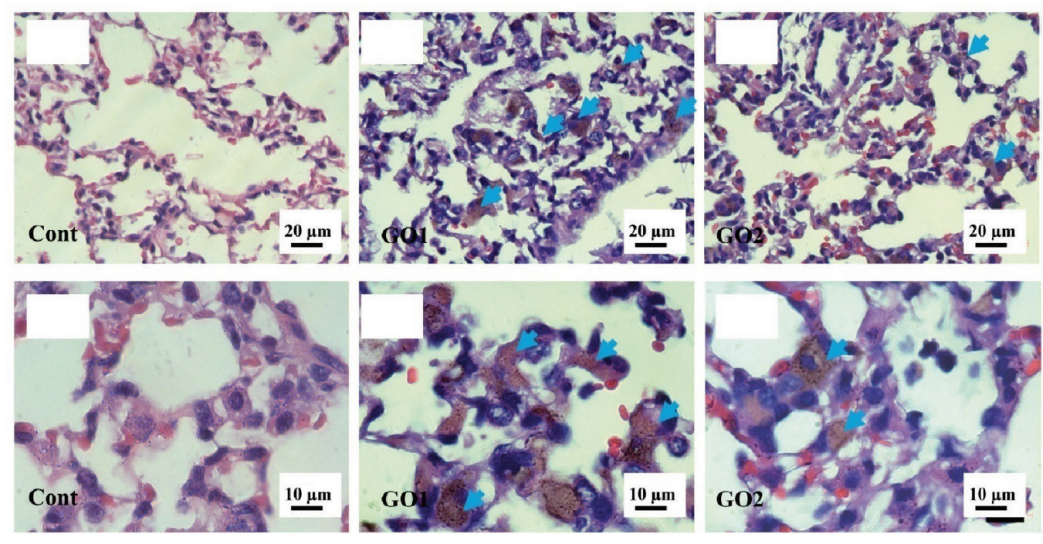

Figure 3. Representative histological images of lungs from mice treated with GO suspended in PBS (G01) and PBS containing Tween 80 (GO2). Hematoxylin and eosin stains of lungs tissues of control mice treated with PBS containing $1 \%$ Tween 80 (a, d), G01 (b, e) and GO2 (c, f). Arrows show GO aggregations [30].

Lin et al. [31] examined the in vitro toxicity (in human retinal pigment epithelium (RPE) cells) and in vivo biocompatibility of hydroxylated graphene (G-OH) administered to Zelanian rabbits. They found that an amount of 10, 20 and $50 \mu \mathrm{g} \mathrm{mL}^{-1}$ of G-OH did not cause RPE cell apoptosis and DNA damage within $48 \mathrm{~h}$ while a minor degree of cell apoptosis and DNA damage were observed when cells were exposed to more than $50 \mu \mathrm{g} \mathrm{mL}^{-1}$. The expression of both caspase-3 and p53 showed increasing trends that were both dose- and time-dependent. Comet and highly reactive oxygen species (ROS) assays also exhibited dose-dependent increasing trends, although no time-dependent change was observed. Possible genotoxicity induced by G-OH might have occurred when the concentration of G-OH was higher than $100 \mu \mathrm{g} \mathrm{mL}^{-1}$. They also found that intravitreous injection of $\mathrm{G}-\mathrm{OH}$ caused few changes to eyesight-related functions such as intraocular pressure, electroretinography and retinal structures. Figure 4 presents transmission electron microscopy (TEM) images of ARPE-19 cells exposed to G-OH for various periods of time. When cells were exposed for $24 \mathrm{~h}, \mathrm{G}-\mathrm{OH}$ was mainly located around the cells. No visible damage or changes to cell morphology were observed, although liquor bubble was increased and expanded. Increased amounts of phagocytic vacuoles with $\mathrm{G}-\mathrm{OH}$ and $\mathrm{G}-\mathrm{OH}$ inside karyotheca were observed when cells were exposed for $48 \mathrm{~h}$. No G-OH inside the cell was visible when the incubation time was increased to $72 \mathrm{~h}$. G-OH was released from the cell while the nucleus and organelles remained intact. This finding suggested that penetration of G-OH into and out of the cytoplasm by means of endocytosis and exocytosis did not damage cell membranes [31]. 


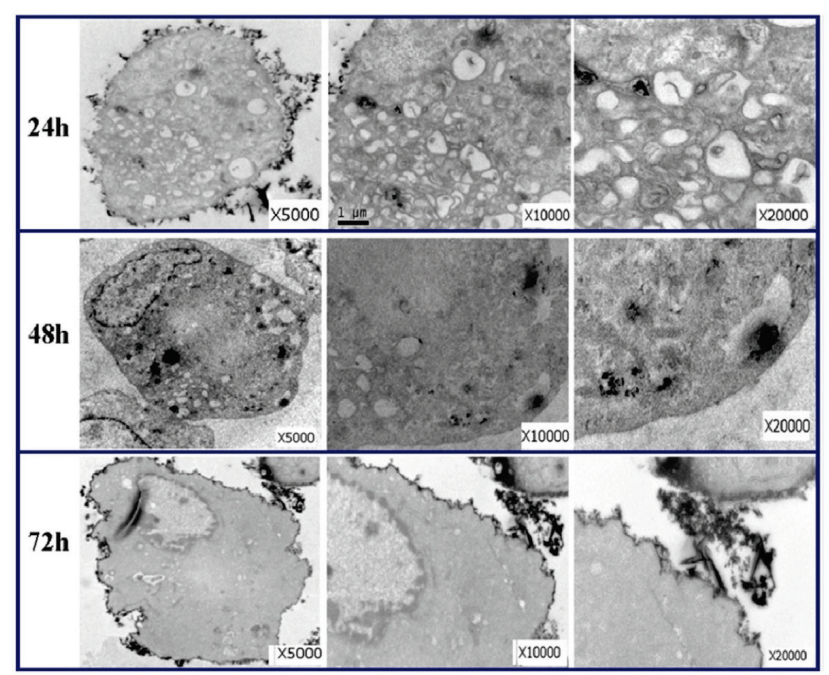

Figure 4. TEM images of APRE-19 cells treated with G-OH for different periods of time [31]

Hu et al. [32] investigated the effect of graphene on in vivo metabolism in wheat roots. They found that graphene upregulated the content of ribose, which contributed negatively to the number of wheat roots; this could be a result of cell dysfunction. Functionalization of graphene with humic acid (HA) resulted in an enhancement in the anabolism of inositol and an increase in the number of wheat roots, suggesting that HA protects the function of cell membranes exposed to graphene. Their metabolic analysis confirmed that the products of phosphoenolpyruvic acid catabolism, i.e. phenylalanine and lanostane, increased the number of wheat roots. For graphene analysis, an enhancement in the content of alkane influenced the biosynthesis of downstream fatty acids and reduced cell membrane fluidity and permeability. Graphene-HA promoted lysine anabolism and the number of wheat roots compared with the blank and graphene. Graphene and graphene-HA, respectively, enhanced and inhibited the biosynthesis of cadaverine, which is a toxic diamine produced by the decarboxylation of lysine in plants during decomposition. Compared with control results, graphene and graphene-HA enhanced and inhibited the biosynthesis of gluconic acid, respectively. Thus, HA may regulate the direction of glucose metabolism fluxes. The content of mannose, which plays osmoprotective and antioxidant roles in extrinsic stress, was up- and downregulated by graphene-HA and graphene, respectively. Graphene and graphene-HA reconstituted the metabolic flux of glycometabolism, fatty acids, amino acids and the tricarboxylic acid cycle, which affected the biosynthesis of chlorophyll. Another study by $\mathrm{Hu}$ [33] revealed that GO greatly amplifies the phytotoxicity of arsenic (As), a 
widespread contaminant, in wheat, causing a decrease in biomass and root numbers and increased oxidative stress, which are thought to be regulated by metabolism. Compared with the control / As-only / GO-only treatments, AsGO inhibited carbohydrate metabolism, except for galactofuranoside. The inhibition of carbohydrate metabolism was linked to the insufficiency of energy supplementation, which was consistent with growth inhibition. Carbohydrate metabolism is also considered to be an indicator of osmoprotection. Thus, the results indicate that AsGO increased cellular electrolyte leakage. AsGO enhanced amino acid and secondary metabolism, including that of leucine, glycine, phenylalanine, naphthalene and octadecamethyl-cyclononasiloxane, events that are associated with the cellular response to stress. AsGO significantly enhanced the accumulation of a saturated fatty acid (alkane), which was related to a reduction in membrane fluidity, which most likely led to membrane structural damage. AsGO also disturbed the urea cycle and induced the accumulation of amino acids, such as lysine, threonine, asparagine and isoleucine. Specifically, the pathway of nitrogen storage was altered.

\subsection{GRAPHENE AND GRAPHENE OXIDE IN TARGETED DRUG DELIVERY}

Chemotherapy is commonly used in the treatment of various types of cancers, although the delivery of an effective dose of conventional chemotherapeutic drugs to tumors is challenging due to the presence of multiple barriers. The construction of new and effective drug delivery systems (DDS) with the ability to improve the therapeutic profile and efficacy of therapeutic agents is one of the most challenging issues faced by medicine nowadays. The ideal DDS should exhibit several properties for efficient cancer therapy, e.g. targeted delivery of the drug (precisely into tumor cells without damaging healthy tissue), efficient loading of the anticancer drug and controlled release of the drug at the required dosage. In order to achieve precise, controlled drug delivery, drug carriers based on nanomaterials are being increasingly investigated because of their unique structures and tunable properties.

One-atom thickness and two-dimensional planes provide graphene with a large specific surface area for the immobilization of a large number of substances, including a wide range of nanoparticles, biomolecules, fluorescent dyes and drugs. Among various subtypes of graphene-based materials, GO has attracted considerable attention and has been widely investigated in the realm of nanomedicine. Aromatic anticancer drugs can be loaded non-covalently onto GO via $\pi-\pi$ stacking and/or van der Waals interactions. Moreover, functional groups such as epoxide, hydroxyl and carboxyl [34] at the basal plane and edges of GO enables the formation of strong hydrogen bond interactions and covalent grafting with various drugs. 
Pristine graphene is highly hydrophobic and water insoluble due to the strong $\pi-\pi$ interactions between graphene sheets. GO and its chemically converted derivatives form stable suspensions in pure water, but they generally tend to aggregate in saline or other biological solutions. In addition, many anticancer drugs exhibit low water solubility and poor bioavailability; moreover, the emergence of drug resistance in patients significantly decreases their therapeutic efficacy. Therefore, a variety of approaches have been elaborated to prepare water soluble graphene and to improve the stability of graphene, its derivatives and hybrids in buffer solutions and biological media. For example, synthetic polymers or biopolymers have been widely used to stabilize and improve the performance of GO and RGO as nanocarriers in nanomedicine [35-37]. Numerous attempts have been made to build graphene-based nanocarrier systems with good water solubility with the usage of PEG [38-40], a hydrophilic biocompatible polymer extensively conjugated with various nanomaterials in order to reduce their non-specific adsorption to biological molecules and cells, and to improve their biocompatibility and in vivo pharmacokinetics for better tumor targeting. To investigate the biodistribution and clearance of PEGylated graphene, hematoxylin and eosin stained images of several organs from mice in the control and treated groups 3, 7, 20, 40 and 90 days after the injection of nanographene sheets-PEG (NGS-PEG) at the dose of $20 \mathrm{mg} \mathrm{kg}^{-1}$ were collected [38]. No significant toxic effect on the organs was observed at various time points after the injection of NGS-PEG, except for some brown-black spots in the liver and spleen noted at early time points. Overall, there were no apparent histopathological abnormalities or lesions in the treated groups at the tested NGS-PEG dose (Figure 5).

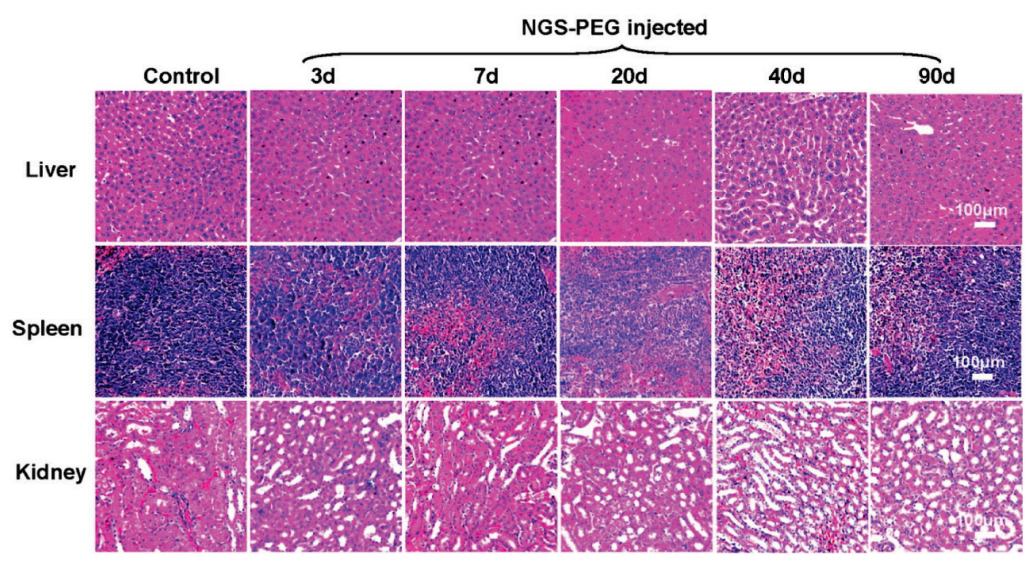

Figure 5. Representative hematoxylin and eosin stained images of major mouse organs: liver, spleen, and kidney collected from control untreated mice and NGS-PEG injected mice at various time points post-injection. The dose of NGS-PEG was

$20 \mathrm{mg} \mathrm{kg}^{-1}$. No obvious organ damage or lesions were observed for NGS-PEG treated mice [38]. 
The first reports on applying this polymer to enhance the performance of graphene materials comes from the Dai group [41,42]. Both publications present the preparation of biocompatible nanoGO conjugated with six-armed PEG-amine stars via carbodiimide catalyzed amide formation. It was confirmed that the enhancement of aqueous stability to the nanoGO in buffer solutions and other biological environments can be achieved by this process. The first publication also presents studies on the conjugation of NGO-PEG hybrid with SN38, a camptothecin (CPT) analogue. The study revealed high potency regarding cancer cell damage, similar to that of free SN38 in an organic solvent. The second publication described work on loading doxorubicin (DOX) onto ultrasmall nanoGO sheets functionalized with PEG. One of the latest reports [43] proposed a new DDS based on PEGylated GO loaded with paclitaxel (PTX) tested on human lung cancer A549 and human breast cancer MCF-7 cells. GO-PEG-PTX presented higher cytotoxic effect on both cells in comparison with free PTX in time- and concentration-dependent manner. One of the first reports on improving the aqueous stability of graphene/GO-based nanocarrier systems by coating with natural polymers other than PEG was published by Bao et al. [44], who confirmed the enhanced aqueous solubility and biocompatibility of chitosan-functionalized GO. Additionally, Zhang et al. [45] used dextran to achieve a similar goal. Recently, in order to improve the colloidal stability of graphene, the group of Maity [46] covered nanosheets with a carbohydrate coating composed of a mixture of chitosan and dextran. The abundance of hydrophilic groups present in dextran and chitosan made the hybrid highly water soluble, while the presence of primary amine groups on chitosan enabled further covalent functionalization of the system. Similar to the roles of PEG, chitosan or dextran in graphene-based DDSs, poly(ethylene imine) [47,48], heparin [49,50], dimethylaminoparthenolide (DMAPT) [51] and starch (a linear polymer formed by $\alpha-1-4$ glycosidic bonds between D-glucose units) [52] can also be used. Wojtoniszak et al. [53] found that the dispersion of GO covalently conjugated with methotrexate (MTX) in biocompatible polymers (PEG and poly(styrenesulfonate) (PSS)) resulted in an extension of the MTX release time in comparison to the suspension in phosphate buffered saline (PBS). The anti-proliferative activity of the anticancer drug bound to GO depended on the dispersant used to stabilize the suspension. Recently, cyclodextrin and cyclic oligosaccharides have also been used in DDS [54] in order to prevent the intermolecular aggregation of GO sheets in water, which then facilitates the disruption of a pristine GO sheet into smaller components during sonication. The targeting ability of the system was achieved due to the presence of hyaluronated adamantane (HA-ADA) chains, since the HA skeleton can precisely recognize the HA receptor expressed by tumor cells during cancer metastasis.

It has been established that the size of the nanocarrier plays an important role in controlling the in vivo fate [55] and in overcoming the barriers of the reticuloendothelial system to transport anticancer drug molecules deeply into 
tumor cells by means of intravenous injection [56]. Nanomaterials with a size smaller than $100 \mathrm{~nm}$ are now considered more suitable for extravasation from the bloodstream into tumors through the enhanced permeation and retention (EPR) effect [57]. It is believed that nanocarriers with a size smaller than $100 \mathrm{~nm}$ can enhance the therapeutic effect, so they have been the focus of considerable research efforts in recent years. For example, Zhao et al. [58] presented a DDS based on biocompatible GO nanoparticles (GON) prepared under strong oxidizing conditions and with a prolonged oxidation time. The material exhibited a nearly spherical shape with a size of $c c a .43 \mathrm{~nm}$. It was then conjugated onto a functional polymer synthesized from PEGylated alginate brushes (ALG-PEG) and cytamine (Cy), forming a biocompatible, 3-D nanoscaled nanocarrier for the efficient loading and triggered release of DOX. The functional polymer Cy-ALG-PEG was grafted onto GON via reduction-sensitive disulfide bonds, so the nanocarrier was responsive to the cleavage of the disulfide bond to detach the Cy-ALG-PEG polymer moieties under reducing conditions. Once being taken up by tumor cells, the Cy-ALG-PEG brushes detached to release the loaded DOX. The majority of researchers focused on exploring the potential applications of graphene in the field of drug delivery have investigated graphene / GO sheets with a size less than $100 \mathrm{~nm}$ $[41,51,54]$.

We can differentiate two targeting approaches: passive strategies based on EPR and active strategies that take advantage of the overexpression of receptors on cancer cells. Therefore, nanomaterials with targeting moieties, such as antibodies, peptides, and other ligands, are able to recognize and bind to tumor tissue through specific interactions between targeting moieties and receptors on the tumor. For example, Zhang et al. [59] built a nanocarrier for mixed anticancer drugs, i.e. DOX and CPT, based on folic acid (FA) covalently grafted to nanoscale GO (NGO) functionalized with sulfonic acid groups. The sulfonic acid groups rendered NGO stable in physiological solutions, while the FA moieties allowed it to specifically target MCF-7 cells, i.e. human breast cancer cells with FA receptors. It was demonstrated that FA-NGO loaded with the two anticancer drugs showed specific targeting to MCF-7 cells and remarkably high cytotoxicity compared to NGO loaded with either DOX or CPT only. The Maity group [46] also used FA to provide targeting specificity in their graphene-based nanocarrier with a carbohydrate coating for both hydrophobic and hydrophilic drugs such as paclitaxol, CPT, DOX, curcumin. Yang et al. [60] added FA-modified $\beta$-cyclodextrin to their graphene-based nanocarrier for DOX as a target unit. The research team of Robinson [61] applied a targeting peptide composed of the Arg-Gly-Asp (RGD) motif to nano-rGO, which provided selective cellular uptake in U87MG cancer cells and highly effective photoablation of cells in vitro. Sun et al. [42] loaded DOX onto nano-GO with high capacity. Antibody-guided targeting selectively transported the anticancer drug into specific cancer cells. Despite the well-established good performance of the abovementioned targeting moieties, they have also exhibited some 
drawbacks. The usage of FA is economically preferable, but its poor water solubility limits its wide application. Peptides have limited target cell types, while the main disadvantage of applying antibodies is their cost. On the other hand, the hyaluronic acid (HA) moiety, which also exhibits specific recognition of receptors overexpressed on the surface of various tumor cells, possesses better water-solubility and stability. It is also preferable from the economical point of view and ubiquitously available. In a study presented by Song et al. [62], a system has been developed based on the conjugation of HA to GO via hydrogen bonding and loading with DOX. In vitro studies (cellular uptake and cytotoxicity assays) on model cells revealed that the HA-GO-DOX system transported DOX specifically to target HepG2 cells, and then efficiently inhibited their proliferation. Simultaneously, the viability of control cells remained high, suggesting a reduction in the side effects of anticancer drug on normal tissue. The tumor inhibition rates of HA-GO-DOX, GO-DOX and free DOX were evaluated in an in vivo study using an $\mathrm{H} 22$ hepatic cancer cell-bearing mouse model. The studies showed that the highest anticancer efficacy was exhibited by the hybrid developed with HA. HA was also applied in DDS by the group of Jung [63], who constructed a nanoGO-hyaluronic acid (NGO-HA) conjugate loaded with epirubicin, a cancer drug favored over DOX, by $\pi-\pi$ stacking. In vitro tests confirmed the $\mathrm{pH}$-dependent drug release and target-specific anti-cancer effect of the complex on B16F1 cells. The enhanced release of epirubicin under acidic conditions might be beneficial for the target-specific intracellular delivery of cancer drugs.

One of the most promising directions in targeted drug delivery is the construction of magnetic-functionalized graphene-based hybrids loaded with anticancer drugs. The first report in this field was published by the group of Yang [64], who developed a hybrid of $\mathrm{GO}$ with $\mathrm{Fe}_{3} \mathrm{O}_{4}$ nanoparticles by a chemical deposition method and conjugated it with DOX hydrochloride (DXR). High drug loading and a large amount of $\mathrm{Fe}_{3} \mathrm{O}_{4}$ nanoparticles deposited on the graphene sheets were obtained simultaneously. This system exhibited superparamagnetic properties, it tended to congregate at acidic $\mathrm{pH}$ values and could be redispersed at basic $\mathrm{pH}$ values. The $\mathrm{GO}-\mathrm{Fe}_{3} \mathrm{O}_{4}$ hybrid and GO- $\mathrm{Fe}_{3} \mathrm{O}_{4}$-DXR moved under the influence of an external magnetic field after congregating under acidic conditions. The observed pH-triggered controlled magnetic behavior allows us to consider this material as a promising candidate for targeted drug delivery purposes. Ma et al. [65] also synthesized a hybrid based on GO and iron nanoparticles for magnetically targeted drug delivery. Additionally, they functionalized it with PEG to acquire high stability in physiological solutions. As in the previous report, the hybrid was loaded with DOX. Pluronic F127 [66] and poly(ethylene imine) [44] have also been studied as agents to provide physiological dispersivity and stability in such systems. A very interesting approach based on combining the therapeutic effect of two anticancer drugs, CPT and methotrexate (MTX), loaded onto an ultrafine GO-magnetic nanoparticle nanocomposite was recently presented by Shen et 
al. [67]. The in vivo assay conducted on male S-180 sarcoma-bearing Balb/c mice showed specific accumulation capacity to the tumor site by the induction of an external magnetic field (Figure 6). Increased drug and magnetic nanoparticle accumulation in that field and the consequent dual-drug synergistic effect and hyperpyrexia significantly contributed to an increase in the inhibition of tumor cell growth and the induction of necrosis. A $\mathrm{pH}$-dependent drug release pattern was observed, in which the anticancer drugs MTX and CPT were released around tumor tissues.

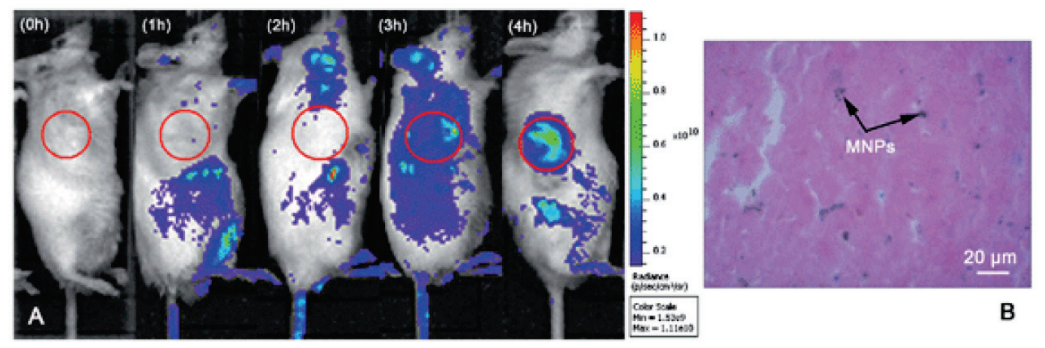

Figure 6. (A) Typical in vivo images of male S-180 sarcoma-bearing Balb/c mice treated with magnetic field at defined time periods $(0,1,2,3$, and $4 \mathrm{~h})$ after intravenous injection of the RhB-labeled MTX@uGO-COOH@MNP@OA@CPT composite. The tumor sites are indicated by red circles. Color coding of fluorescence indicates high levels of fluorescence in red and low levels in blue. Excitation $=570 \mathrm{~nm}$, emission $=650 \mathrm{~nm}$. (B) Representative microscopic image of histochemical analysis of tumor tissue induced with a magnetic field for $4 \mathrm{~h}$ after intravenous administration (H\&E and Prussian blue stain, 40× [67].

Wang et al. [68] improved the delivery efficacy and targeting of the drug carrier based on $\mathrm{GO}-\mathrm{Fe}_{3} \mathrm{O}_{4}$ by conjugating the hybrid with $\mathrm{FA}$ via chitosan as a bridge, followed by loading with DOX. This is an example of the successful combination of active targeting (FA) and passive targeting (magnetic nanoparticles) strategies in drug delivery. Chitosan enhanced the stability and biocompatibility of the complex and also encapsulated and controlled the release of drug molecules. Studies revealed high loading efficiency, prolonged release rate and a $\mathrm{pH}$-dependent mechanism of drug release; $\mathrm{pH}$-activated drug release was also observed by Fan et al. [69] and Wang et al. [70], who presented the preparation of DDSs based on magnetic-functionalized graphene and 5-fluorouracil (5-FU). Xu et al. [71] investigated a similar DDS with levofloxacin (LOFX) and Chen et al. [72] described the construction of multifunctional stimuli-responsive nanosystems. 
Recent advances in the field of designing graphene-based nanocarriers dedicated for drug delivery applications have led to opening up exciting opportunities for the future and the broad usage of this kind of nanomaterial in real clinical conditions.

\subsection{GRAPHENE AND GRAPHENE OXIDE IN PHOTODYNAMIC AND PHOTOTHERMAL THERAPY}

Photothermal (PTT) and photodynamic (PDT) therapies are emerging non-invasive modalities for the treatment of various cancers. PDT involves the utilization of a photosensitizer (PS) which is excited with light of appropriate wavelengths, then emits fluorescence via the relaxation of the excited-singlet-state PS back to the ground state. PS can transfer the absorbed photon energy to oxygen in the surrounding tissue. The generation of ROS such as singlet oxygen and free radicals can oxidize cellular and sub-cellular compartments, resulting in irreversible damage to tumor cells [73,74]. Unlike photosensitizers, a PTT agent absorbs the light, which is then transformed into heat and transferred to the intercellular environment, which induces localized hyperthermia [75].

The first report on graphene utilization in PTT therapy was presented by Young et al. [76]. They examined nanographene sheets (NGS) functionalized with PEG conjugated via amide formation. The material exhibited high solubility and stability in physiological solution and displayed strong near infrared (NIR) radiation absorption. Moreover, it showed efficient tumor passive targeting and relatively low retention in the RES, which was hypothetically caused by the unique two-dimensional shape, small size (10-50 nm) and biocompatible PEG coating that favored the EPR effect of NGS. Therefore, an in vivo PTT therapy study was performed using mice bearing tumors (4T1). After exposure to the laser $(808 \mathrm{~nm})$, the surface temperature of tumor in NGS-PEG injected mice reached $\sim 50{ }^{\circ} \mathrm{C}$, compared to a $\sim 2{ }^{\circ} \mathrm{C}$ rise for irradiated tumors in uninjected mice. All tumors of mice injected with NGS disappeared after 1 day and no tumor regrowth was noted over a course of 40 days, in contrast with control group where rapid tumor growth was observed. The in vivo results showed that PEGylated NGS is an excellent PTT therapy agent without exerting any noticeable toxic effects in treated mice.

Sahu et al. [77] functionalized nanoGO sheets (nanoG0) with Pluronic block copolymer and complexed them with methylene blue (MB) via electrostatic interactions. The nanoGO-MB hybrid showed $\mathrm{pH}$ responsive properties, as the release rate increased considerably under acidic conditions. This nanocomplex showed enhanced uptake of cancer cells compared to normal cells, and in the absence of light, it showed no major toxicity in cells. Intravenous injection of the composite into tumor bearing mice led to high tumor accumulation. PTT treatment resulted in a decrease in tumor growth but failed to abolish the 
tumor. A slight decrease in tumor growth as compared to control group was observed after $10 \mathrm{~min}$ of laser exposure during PDT treatment. The combination of near-infrared (NIR) light-induced PDT therapy and subsequent PTT therapy led to complete ablation of the tumor as well as no regrowth of the tumor in 15 days, indicating the synergistic effect of dual phototherapy.

Jiang with co-workers [78] investigated graphene coated with tetrasulfonic acid tetrasodium salt copper phthalocyanine (TSCuPc) in combined in vitro PTT / PDT therapy. In this system, GR acted as a photosensitizer carrier and PTT agent, while TSCuPc acted as a hydrophilic PDT agent. In vitro cytotoxicity of PTT and PDT was determined with HeLa cells incubated in culture medium containing a series concentration of GR-TSCuPc for $24 \mathrm{~h}$, and then irradiated with a $650 \mathrm{~nm}$ laser for $5 \mathrm{~min}$. The cell viability results showed that the phototherapy effect of GR-TSCuPc was noticeably higher than that of free TSCuPc, indicating that combined non-invasive PTT / PDT exhibits better anticancer efficacy.

Golavelli et al. [79] immobilized a hydrophobic silicon napthalocyaninebis (trihexylsilyloxide) (SiNc4) photosensitizer onto water dispersible magnetic and fluorescent graphene (MFG) via $\pi-\pi$ stacking to yield the MFG-SiNc4 nanohybrid, using a non-covalent approach for single light-induced PTT / PDT. The phototherapeutic capability MFG-SiNc4 was further assessed in HeLa cells by monitoring cell viability under dark/light conditions. It was found that, under photoirradiation with a $775 \mathrm{~nm}$ laser, MFG-SiNc4 exerted a cytotoxic effect on HeLa cells. The PTT / PDT capabilities with appreciable cell killing efficacy was about $97.9 \%$; of this, $64.7 \%$ was due to PDT and $33.2 \%$ was due to PTT, suggesting that the decrease in cell viability by MFG-SiNc4 was mostly due to the toxicity induced by ${ }^{1} \mathrm{O}_{2}$ and other ROS. However, the inherent PTT capability of MFG, owing to its enhanced $\pi$-electrons and NIR adsorption, also contributed to some extent to the decrease in cell viability. Thus, immobilizing SiNc4 onto graphene facilitated the utilization of a single light source to simultaneously generate the PTT/PDT effect.

In another study, Yan and co-workers [80] designed a photo-theranostic platform based on sinoporphyrin sodium (DVDMS) photosensitizer-loaded PEGylated GO (GO-PEG-DVDMS) for combined PDT and PTT. After loading DVDMS onto GO-PEG an increase in optical absorption at $808 \mathrm{~nm}$ was observed with an increase in DVDMS loading. This resulted in the improved PTT effect of GO-PEG-DVDMS. Moreover, DVDMS anchoring onto GO-PEG did not inhibit the evolution of singlet oxygen. Interestingly, an in vivo study on PC9 tumor-bearing mice revealed that GO-PEG-DVDMS had highly efficient passive tumor targeting ability and a long retention time in the tumor tissue. It is worth noting that, during PTT treatment, all tumors treated with GO-PEG-DVDMS and laser irradiation $(808 \mathrm{~nm})$ were effectively ablated, leaving black scars at the original tumor sites; however, one week after treatment, the wounds had fully recovered. Furthermore, complete tumor regression was achieved by 
intravenous injection of GO-PEG-DVDMS, at low injection dose of $1 \mathrm{mg} \mathrm{kg}^{-1}$ of GO-PEG and $2 \mathrm{mg} \mathrm{kg}^{-1}$ of DVDMS, in PDT treatment followed by PTT.

Zhen et al. [81] prepared FA-GO-PEG-fullerene (FA-GO-PEG/C $\mathrm{C}_{60}$ ) nanohybrids for targeting photothermally enhanced PDT therapy. In this work, FA and PEG were conjugated onto GO via an imide linage. Then, the FA-GO-PEG/ $\mathrm{C}_{60}$ nanohybrid was prepared by using nucleophilic addition. FA and PEG-functionalized graphene was used as nanocarrier of tumor-targeting $\mathrm{C}_{60}$ which offered improved HeLa cells uptake. After irradiation with a $532 \mathrm{~nm}$ laser, FA-GO-PEG/ $\mathrm{C}_{60}$ caused a marked decrease in cell survival and elevation in oxidative stress, which induced apoptotic death. Compared with PDT or PTT alone, the combined treatment with $\mathrm{FA}-\mathrm{GO}-\mathrm{PEG} / \mathrm{C}_{60}$ showed increased cell apoptosis and death, indicating a synergistic effect of combination phototherapy. Based on this study, the hypothetical mechanism of PTT and PDT combined therapy of FA-GO-PEG/ $\mathrm{C}_{60}$ is shown in Figure 7. The combination of graphene with fullerene $\mathrm{C}_{60}$ provides remarkable synergies in phototherapy. Firstly, the hybridization process prevents the restacking of graphene and the aggregation of $\mathrm{C}_{60}$, which supply more surface active sites and increase the PDT efficiency of FA-GO-PEG/ $\mathrm{C}_{60}$. Secondly, owing to the doping effect, the $\mathrm{FA}-\mathrm{GO}-\mathrm{PEG} / \mathrm{C}_{60}$ exhibits a broader absorption range and higher absorbance. Thirdly, the PTT effects of FA-GO-PEG/ $\mathrm{C}_{60}$ cause obvious cell damage and achieve synergistic enhancement of the phototherapy effects. Fourthly, the graphene carrier equipped with FA and PEG is specifically targeted to tumor cells, which significantly enhances the cellar uptake of FA-GO-PEG/ $\mathrm{C}_{60}$. Once the $\mathrm{FA}-\mathrm{GO}-\mathrm{PEG} / \mathrm{C}_{60}$ is taken up by tumor cells, it increases in temperature and causes considerable intracellular ROS production under light irradiation. The photogenerated ROS and heating cause a marked decrease in cell survival and increased oxidative stress. Finally, the phototherapy effects of $\mathrm{FA}-\mathrm{GO}-\mathrm{PEG} / \mathrm{C}_{60}$ apparently involve the induction of apoptosis [81]. 


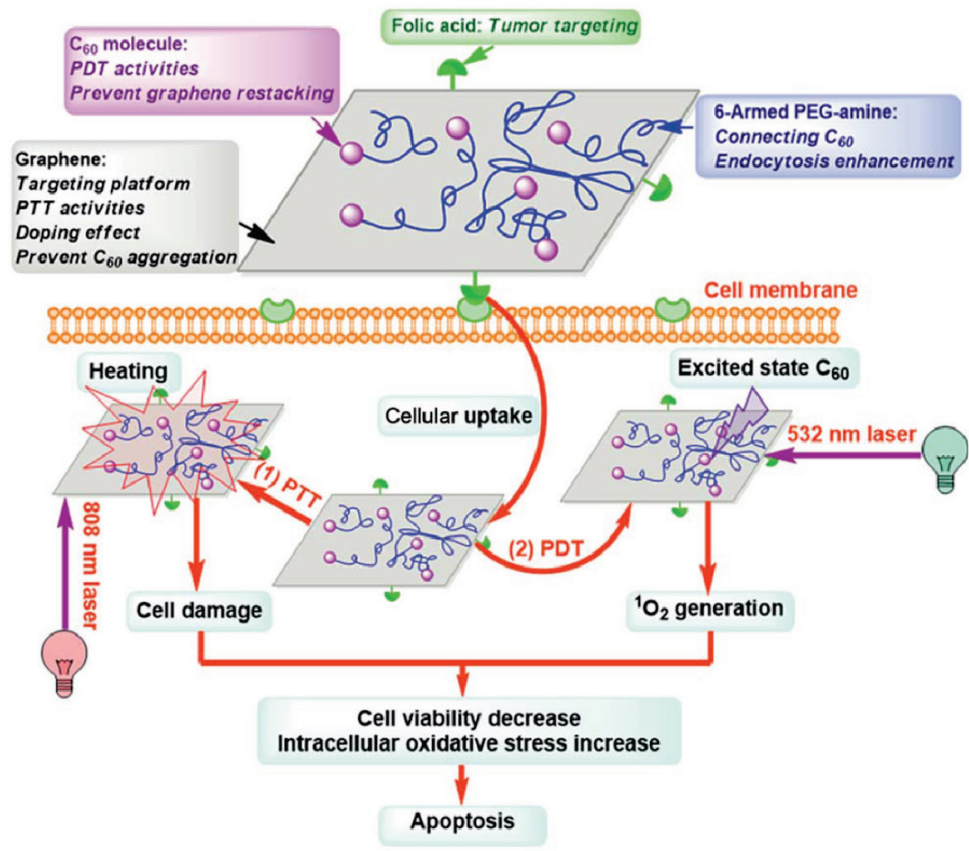

Figure 7. The hypothetical mechanism of synergistic enhancement of FA-GO-PEG/C 60 in combined PTT and PDT [81]

Rong et al. [82] confirmed that PEGylated GO is a good nanocarrier for photosensitizer molecules and enhances its cellular uptake. They loaded 2-(1-hexyloxyethyl)-2-devinyl (HPPH) onto GO-PEG to produce a GO-PEGHPPH nanocomposite. The nanoplatform allowed for increased uptake of the HPPH into 4T1 murine mammary cancer cells through a more active endocytosis process compared to free $\mathrm{HPPH}$, which accumulated through passive diffusion. Moreover, the cancer cells exposed to $671 \mathrm{~nm}$ laser for $3 \mathrm{~min}$ exhibited much lower viability when treated with GO-PEG-HPPH than with free HPPH and GO-PEG. In vivo study confirmed the accumulation of GO-PEG-HPPH in tumors, while a very small amount of the hybrid was observed in organs such as the liver and spleen, indicating high tumor selectivity. In vivo PDT study was carried out in 4T1 bearing mice intravenously injected with GO-PEG-HPPH or free HPPH at the same HPPH concentration. Mice were irradiated with a $671 \mathrm{~nm}$ laser $24 \mathrm{~h}$ after injection for $20 \mathrm{~min}$. Tumors treated with GO-PEG-HPPH and irradiation were effectively ablated. However, the HPPH treated group showed negligible damage to the tumors and delayed tumor growth compared with the control groups. Importantly, the complex did 
not exhibit toxicity to the treated mice, including no damage to the liver, spleen, kidney, heart or lung.

In another paper, Taratula with co-workers [83] developed novel low-oxygen graphene nanosheets (LOGr) chemically modified with poly(propyleneimine) dendrimers (LHRH) loaded with phthalocyanine (Pc) as a photosensitizer for imaging and PTT/PDT combination therapy. To evaluate the efficiency of the new nanoplatform as a PTT/PDT agent, the phototherapeutic effect of the LOGr-Pc-LHRH complex on ovarian cancer cells was examined. When the two treatments were combined under single $690 \mathrm{~nm}$ light irradiation, ovarian cancer cell viability was significantly reduced as compared with LOGr-Pc-LHRH (PTT) and LOGr-Pc-LHRH(PDT) treatment applied separately. Moreover, the cytotoxicity of LOGr-LHRH, Pc-LHRH, and LOGr-Pc-LHRH toward red blood cells was investigated using hemolysis studies and it was found that the nanoplatforms exhibited minimal hemolytic activity. The encapsulated photosensitizer, due to its very hydrophobic nature, was not able to escape from the dendrimer-based carrier in an intracellular environment, and hence could not directly induce toxicity.

Table 1. Summary on reviewed applications of graphene and GO, where DDS corresponds to DDS, TDDS-targeted DDS, PTT-PTT therapy, PDT-PDT therapy

\begin{tabular}{cccc}
\hline Material & Application & Cell line & References \\
\hline NGO-PEG-SN38 & DDS & $\begin{array}{c}\text { HCT-116, OVCAR-3, } \\
\text { U87MG, MDA-MB-435, } \\
\text { MCF-7 and MDA-MB-468 } \\
\text { cancer cell lines }\end{array}$ & {$[41]$} \\
\hline NGO-PEG-DOX & DDS & Raji and CEM & {$[42]$} \\
\hline NGO-PEG-PTX & DDS & MCF 7 & {$[43]$} \\
\hline GO-CS-CPT & DDS & HepG2 & {$[44]$} \\
\hline GO-DEX-CS-Folate & DDS & HeLa & {$[46]$} \\
\hline GO-PEI-UCNPs-DOX & DDS & MCF 7 & {$[47]$} \\
\hline GO-PEI-pDNA & DDS & HeLa & {$[48]$} \\
\hline rGO-LHT7-DOX & DDS & KB cells and & {$[50]$} \\
\hline G-COOH-PTL & DDS & Panc-1 & {$[51]$} \\
\hline $\begin{array}{c}\text { Starch- } \\
\text { functionalized } \\
\text { graphene-HCPT }\end{array}$ & DDS & SW-620 & {$[52]$} \\
\hline $\begin{array}{c}\text { GO-PEG-MTX and } \\
\text { GO-PSS-MTX }\end{array}$ & DDS & MCF 7 & {$[53]$} \\
\hline CPT-GO-CD-HA-ADA & TDDS & MDA-MB-241 & {$[54]$} \\
\hline PEG-ALG-GON-DOX & TDDS & HepG2 & {$[58]$} \\
\hline
\end{tabular}




\begin{tabular}{|c|c|c|c|}
\hline Material & Application & Cell line & References \\
\hline FA-NGO-DOX-CPT & TDDS & MCE-7 & {$[59]$} \\
\hline CD-ADA-PP-GO-DOX & DDS & HeLa-bearing mice & {$[60]$} \\
\hline $\begin{array}{c}\text { RGD- or RAD- } \\
\text { functionalized GO }\end{array}$ & TDDS & U87 Mg & [61] \\
\hline HA-GO-DOX & TDDS & H22-bearing mice & {$[62]$} \\
\hline NGO-HA-DOX & TDDS & B16F1 & {$[63]$} \\
\hline GO-Fe-PEG-DOX & TDDS, PTT, MRI & $4 \mathrm{~T} 1$ & {$[65]$} \\
\hline $\begin{array}{l}\text { MTX@u-GO-COOH- } \\
\text { MNP@OA-CPT }\end{array}$ & TDDS, PTT & HepG2 & {$[67]$} \\
\hline $\mathrm{G}-\mathrm{Fe}_{3} \mathrm{O}_{4}-5-\mathrm{FU}$ & TDDS & HepG2 & [69] \\
\hline $\mathrm{GO}-\mathrm{Fe}_{3} \mathrm{O}_{4}-5-\mathrm{FU}$ & TDDS, MRI & - & {$[70]$} \\
\hline $\mathrm{GO}-\mathrm{Fe}_{3} \mathrm{O}_{4}-\mathrm{MnO}_{\mathrm{x}}$ & TDDS, MRI & - & [71] \\
\hline NGS-PEG & PTT & 4T1-bearing mice & {$[76]$} \\
\hline NGO-Pluronic-MB & $\mathrm{PTT} / \mathrm{PDT}$ & $\begin{array}{l}\text { HeLa-bearing mice and } \\
\text { HeLa cells }\end{array}$ & [77] \\
\hline Graphene-TSCuPc & $\mathrm{PTT} / \mathrm{PDT}$ & HeLa cells & [78] \\
\hline $\begin{array}{c}\text { Fe-Graphene- } \\
\text { fluoresceine-SiNC }\end{array}$ & $\mathrm{PTT} / \mathrm{PDT}$ & HeLa cells & [79] \\
\hline GO-PEG-DVDMS & $\mathrm{PTT} / \mathrm{PDT}$ & PC9-bearing mice & {$[80]$} \\
\hline FA-GO-PEG/C 60 & $\mathrm{PTT} / \mathrm{PDT}$ & HeLa cells & [81] \\
\hline GO-PEG-HPPH & PDT & 4T1-bearing mice & {$[82]$} \\
\hline LOGr-Pc-LHRH & PTT/PDT & Ovarian cancer cells & [83] \\
\hline
\end{tabular}

\subsection{SUMMARY}

Extensive research into the toxicity and biocompatibility of graphene and GO has revealed multiple factors influencing their behavior in biological systems. Both in vitro and in vivo studies have shown the size- and dose-dependent toxicity of these nanomaterials. Another significant aspect is the concentration of oxygen-containing functional groups present on the surface of GO or RGO. For instance, blood toxicity studies have shown that graphene is more biocompatible than GO, which is a result of interaction between 0-groups and blood cells. Functionalization of GO improves its biocompatibility, and different materials have been used for that purpose, for instance PEG, PVK, dopamine, heparin or amine modifiers. In vivo studies have revealed that the method of nanomaterial administration influences their behavior in living organisms. For example, PEGylated GO is rapidly excreted after oral administration, while after intraperitoneal administration it is engulfed by phagocytes in the RES and retained for a long period of time. 
GO has been explored as an excellent nanocarrier of drugs by enhancing their cytotoxic effect. However, in order to prevent aggregation in a physiological environment, modification of the GO surface is necessary. The most commonly used materials are biocompatible polymers, such as PEG, chitosan, dextran and poly(ethylene imine). Another advantage of GO utilization as a nanocarrier of drugs is the opportunity to develop a targeted drug delivery system (TDDS). This is possible by functionalizing the nanocarrier with receptors, such as antibodies, peptides and other ligands that are able to specifically recognize tumor cells. Another TDDS is based on the functionalization of GO with superparamagnetic molecules, which enable the delivery of drugs under the influence of an external magnetic field. Furthermore, simultaneous functionalization of GO with an antitumor drug and magnetic particles has an effect on dual-drug synergism and hyperpyrexia, which significantly contributes to increased inhibition of tumor cell growth and the induction of necrosis.

Recent studies have shown that nanocarriers with sizes smaller than $100 \mathrm{~nm}$ can enhance the therapeutic effect. Particles of this size are most suitable for extravasation from the bloodstream into tumors due to the enhanced permeation and retention effect and increased tumor tissue permeation.

Graphene and GO are also appropriate nanocarriers of PDT therapeutic agents, and can enhance their anticancer activity. Simultaneously, they act as PTT agents able to absorb NIR irradiation, producing local hyperthermia resulting in the death of tumor tissues. Many reports have revealed that the combination of PDT and PTT in tumor tissues results in improved anticancer therapy.

Recent studies have demonstrated the great potential of graphene and GO usage in biomedical applications, especially in antitumor therapy, including targeted drug delivery and PDT/PTT therapies. However, the toxicology of these materials is still questionable and needs to be resolved before clinical use. 


\section{REFERENCES}

1. C. Chung, Y.K. Kim, D. Shin, S.R. Ryoo, B.H. Hong, D.H. Min. Acc. Chem. Res. 46 (2012) 2211-2224.

2. N.S.W. Kam, T.C. Jessop, P.A. Wender, H.J. Dai. J. Am. Chem. Soc. 126 (2004) 6850-6851.

3. J. Shi, X. Yu, L. Wang, J. Gao, J. Zhang, R. Ma, R. Liu, Z. Zhang. Biomaterials 34 (2013) 9666-9677.

4. $\quad$ J. Liu, L. Cui, D. Losic. Acta Biomater. 9 (2013) 9243-9257.

5. A. Bianco, H.M. Cheng, T. Enoki, Y. Gogotsi, R.H. Hurt, N. Koratkar, T. Kyotani, M. Monthioux, C.R. Park, J.M.D. Tascon, J. Zhang. Carbon 65 (2013) 1-6.

6. Y. Li, H. Dong, Y. Li, D. Shi. Int. J. Nanomedicine 10 (2015) 2451-2459.

7. K.S. Novoselov, A.K. Geim, S.V. Morozov, D. Jiang, Y. Zhang, S.V. Dubonos. Science 306 (2004) 666-669.

8. H.C. Lin, Y.Z. Chen, Y.C. Wang, Y.L. Chueh. J. Phys. Chem. C 119 (2015) 6835-6842.

9. A.J. Van Bommel, J.E. Crombeen, A. Van Tooren. Surf. Sci. 48 (1975) 463-472.

10. W.A. de Heer, C. Berger, X. Wu, P.N. First, E.H. Conrad, X. Li, T. Li, M. Sprinkle, J. Hass, M.L. Sadowski, M. Potemski, G. Martinez. Solid State Commun. 143 (2007) 92-100.

11. W.S. Hummers, R.E. Offeman. J. Am. Chem. Soc. 80 (1958) 1339-1339.

12. S.F. Pei, H.M. Cheng. Carbon 50 (2012) 3210-3228.

13. B.C. Brodie. Ann. Chim. Phys. 59 (1860) 466-472.

14. L. Staudenmaier. Ber. Dtsch. Chem. Ges. 31 (1898) 1481-1487.

15. K. Wang, J. Ruan, H. Song, J. Zhang, Y. Wo, S. Guo, D. Cui. Nanoscale Res. Lett. 6 (2011) 8-15.

16. Y. Chang, S.T. Yang, J.H. Liu, E. Dong, Y. Wang, A. Cao, Y. Liu, H. Wang. Toxicol. Lett. 200 (2011) 201-210.

17. W. Hu, C. Peng, M. Lv, X. Li, Y. Zhang, N. Chen, C. Fan, Q. Huang. ACS Nano 5 (2011) 3693-3700.

18. O.N. Ruiz, K.A. Shiral Fernando, B. Wang, N.A. Brown, P.G. Luo, N.D. McNamara, M. Vangsness, Y.P. Sun, C.E. Bunker. ACS Nano 5 (2011) 8100-8107.

19. K.H. Liao, Y.S. Lin, C.W. Macosko, C.L. Haynes, ACS Appl. Mater. Interfaces 3 (2011) 2607-2615.

20. M. Wojtoniszak, X. Chen, R.J. Kalenczuk, A. Wajda, J. Łapczuk, M. Kurzewski, M. Drozdzik, P.K. Chuc, E. Borowiak-Palen. Colloids Surf. B 89 (2012) 79-85.

21. C.M. Santos, J. Mangadlao, F. Ahmed, A. Leon, R.C. Advincula, D.F. Rodrigues. Nanotechnology 23 (2012) 395101-395110.

22. C. Cheng, S. Nie, S. Li, H. Peng, H. Yang, L. Ma, S. Sun, C. Zhao. J. Mater. Chem. B 1 (2013) 265-275.

23. S.K. Singh, M.K. Singh, P.P. Kulkarni, V.K. Sonkar, J.J.A. Gracio, D. Dash. ACS Nano 6 (2012) 2731-2740.

24. K. Urbas, M. Aleksandrzak, M. Jedrzejczak, M. Jedrzejczak, R. Rakoczy, X. Chen, E. Mijowska. Nanoscale Res. Lett. 9 (2014) 656-667.

25. X. Zhang, J. Yin, C. Peng, W. Hu, Z. Zhu, W. Li, C. Fan, Q. Huang. Carbon 49 (2011) 986- 995.

26. M.C. Duch, G.R.S. Budinger, Y.T. Liang, S. Soberanes, D. Urich, S.E. Chiarella, L.A. Campochiaro, A. Gonzalez, N.S. Chandel, M.C. Hersam, G.M. Mutlu. Nano Lett. 11 (2011) 5201-5207. 
27. K. Yang, H. Gong, X. Shi, J. Wan, Y. Zhang, Z. Liu. Biomaterials 34 (2013) 2787-2795.

28. Y. Chong, Y. Ma, H. Shen, X. Tu, X. Zhou, J. Xu, J. Dai, S. Fan, Z. Zhang. Biomaterials 35 (2014) 5041-5048.

29. G. Qu, X. Wang, Q. Liu, R. Liu, N. Yin, J. Ma, L. Chen, J. He, S. Liu, G. Jiang. J. Environ. Sci. 25 (2013) 873-881.

30. M. Lin, R. Zou, H. Shi, S. Yu, X. Li, R. Guo, L. Yan, G. Li, Y. Liu, L. Dai. Mat. Sci. Eng. C 50 (2015) 300-308.

31. D.R. Dreyer, S. Park, C.W. Bielawski, R.S. Ruoff. Chem. Soc. Rev. 39 (2010) 228-240.

32. L. Zhang, Z. Wang, Z. Lu, H. Shen, J. Huang, Q. Zhao, M. Liu, N. He, Z. Zhang. J. Mater. Chem. B 1 (2013) 749-755.

33. W. Miao, G. Shim, C.M. Kang, S. Lee, Y.S. Choe, H.G. Choi. Biomaterials 34 (2013) 9638-9647.

34. Y.K. Kim, M.H. Kim, D.H. Min. Chem. Commun. 47 (2011) 3195-3197.

35. K. Yang, J. Wan, S. Zhang, Y. Zhang, S.T. Lee, Z. Liu. ACS Nano 5 (2011) 516-522.

36. S.J. Zhu, H. Zhen, Y.J. Li, P. Wang, X.Y. Huang, P. Shi. J. Nanopart. Res. 16 (2014) 2530-2541.

37. H.L. Xiong, Z.Y. Guo, W. Zhang, H.Q. Zhong, S.H. Liu, Y.H. Ji. J. Photochem. Photobiol. B: Biol. 138 (2014) 191-201.

38. Z. Liu, J.T. Robinson, X. Sun, H. Dai. J. Am. Chem. Soc. 130 (2008) 10876-10877.

39. X. Sun, Z. Liu, K. Welsher, J.T. Robinson, A. Goodwin, S. Zaric, H. Dai. Nano Res. 1 (2008) 203-212.

40. Z. Xu, S. Zhu, M. Wang, Y. Li, P. Shi, X. Huang. ACS Appl. Mater. Interfaces 7 (2015) 1355-1363.

41. H. Bao, Y. Pan, Y. Ping, N.G. Sahoo, T. Wu, L. Li, J. Li, L.H. Gan. Small 7 (2011) 1569-1578.

42. $\quad$ S. Zhang, K. Yang, L. Feng, Z. Liu. Carbon 49 (2011) 4040-4049.

43. A.R. Maity, A. Chakraborty, A. Mondal, N.R. Jana. Nanoscale 6 (2014) 2752-2758.

44. L. Yan, Y.N. Chang, L.N. Zhao, Z.J. Gu, X.X. Liu, G. Tian, L.J. Zhou, W.L. Ren, S. Jin, W. Yin, H. Chang, G. Xing, X. Gao, Y. Zhao. Carbon 57 (2013) 120-129.

45. B.A. Chen, M. Liu, L.M. Zhang, J. Huang, J.L. Yao, Z.J. Zhang. J. Mat. Chem. 21 (2011) 7736-7741.

46. Y. Wang, P. Zhang, C. Fang, C. Liu, L. Zhan, Y.F. Li, C.Z. Huang. RSC Adv. 2 (2012) 2322-2328.

47. G. Shim, J.Y. Kim, J. Han, S.W. Chung, S. Lee, Y. Byun, Y.K. Oha. J. Control. Release 189 (2014) 80-89.

48. A. Karmakar, Y. Xu, T. Mustafa, G. Kannarpady, S.M. Bratton, A. Radominska-Pandya, A. Crooks, A.S. Biris. RSC Adv. 5 (2015) 2411-2420.

49. K. Liu, Y. Wang, H. Li, Y. Duan. Colloids Surf B Biointerfaces 128 (2015) 86-93.

50. M. Wojtnoszak, K. Urbas, M. Peruzynska, M. Kurzawski, M. Droździk, E. Mijowska. Chem. Phys. Lett. 568-569 (2013) 151-156.

51. Y.M. Zhang, Y. Cao, Y. Yang, J.T. Chen, Y. Liu. Chem. Commun. 50 (2014) 13066-13069.

52. V. Mailander, K. Landfester. Biomacromolecules 10 (2009) 2379-2400.

53. J.A. MacKay, M. Chen, J.R. McDaniel, W. Liu, A.J. Simnick, A. Chilkoti. Nat. Mater. 8 (2009) 993-999.

54. $\quad$ S.R. MacEwan, D.J. Callahan, A. Chilkoti. Nanomedicine 5 (2010) 793-806. 
55. X. Zhao, L. Liu, X. Li, J. Zeng, X. Jia, P. Liu. Langmuir 30 (2014) 10419-10429.

56. L. Zhang, J. Xia, Q. Zhao, L. Liu, Z. Zhang. Small 6 (2010) 537-544.

57. Y. Yang, Y.M. Zhang, Y. Chen, D. Zhao, J.T. Chen, Y. Liu. Chem. Eur. J. 18 (2012) 4208-4215.

58. J.T. Robinson, S.M. Tabakman, Y. Liang, H. Wang, H.S. Casalongue, D. Vinh, H. Dai. J. Am. Chem. Soc. 133 (2011) 6825-6831.

59. E. Song, W. Han, C. Li, D. Cheng, L. Li, L. Liu, G. Zhu, Y. Song, W. Tan. ACS Appl. Mat. Interfaces 6 (2014) 11882-11890.

60. H.S. Jung, M.-Y. Lee, W.H. Kong, I.H. Do, S.K. Hahn. RCS Adv. 4 (2014) 14197-14200.

61. X. Yang, X. Zhang, Y. Ma, Y. Huang, Y. Wanga, Y. Chen. J. Mat. Chem. 19 (2009) 2710-2714.

62. X.X. Ma, H.Q. Tao, K. Yang, L.Z. Feng, L. Cheng, X.Z. Shi, Y.G. Li, L. Guo, Z. Liu. Nano Res. 5 (2012) 199-212.

63. Y.Y. Li, J.Q. Liu, H.Q. Dong, G.Z. Liu, H.Q. Hu. Nanotechnology 25 (2014) 065602-065610.

64. J.M. Shen, F.Y. Gao, L.P. Guan, W. Su, Y.J. Yang, Q.R. Li, Z.C. Jin. RSC Adv. 4 (2014) 18473-18484.

65. Z.H. Wang, C.F. Zhou, J.F. Xia, B. Via, Y.Z. Xia, F.F. Zhang, Y.H. Li, L.H. Xia. Colloids Surf. B 106 (2013) 60-65.

66. X.J. Fan, G.Z. Jiao, W. Zhao, P.F. Jin, X. Li. Nanoscale 5 (2013) 1143-1152.

67. G.S. Wang, G.Y. Chen, Z. Wei, X.F. Dong, M. Qi. Mat. Chem. Phys. 141 (2013) 997-1004.

68. G.Q. Xu, P.W. Xu, D.J. Shi, M.Q. Chen. RSC Adv. 4 (2014) 28807-28813.

69. Y. Chen, P.F. Xu, Z. Shu, M.Y. Wu, L.Z. Wang, S.J. Zhang, Y.Y. Zheng, H.R. Chen, J. Wang, Y. Li, J. Shi. Adv. Funct. Mater. 24 (2014) 4386-4396.

70. D.E. Dolmans, D. Fukumura, R.K. Jain, Photodynamic therapy for cancer. Nat. Rev. Cancer. 3 (2003) 380-387.

71. P. Rai, S. Mallidi, X. Zheng, R. Rahmanzadeh, Y. Mir, S. Elrington. Adv. Drug Deliv. Rev. 62 (2010) 1094-1124.

72. N.H. Levi-Polyachenko, J.H. Stewart. Open Nanomed. J. 3 (2011) 24-37.

73. K. Yang, S. Zhang, G. Zhang, X. Sun, S.T. Lee, Z. Liu. Nano Lett. 10 (2010) 3318-3323.

74. A. Sahu, W. Choi, J.H. Lee, G. Tae. Biomaterials 34 (2013) 6239-6248.

75. B.P. Jiang, L.F. Hu, D.J. Wang, S.C. Ji, X.C. Shen, H. Liang. J. Mater. Chem. B 2 (2014) 7141-7148.

76. G. Gollavelli, Y.C. Ling. Biomaterials 35 (2014) 4499-4507.

77. X. Yan, H. Hu, J. Lin, A.J. Jin, G. Niu, S. Zhang, P. Huang, B. Shen, X. Chen. Nanoscale 7 (2015) 2520-2526.

78. Z. Hu, J. Li, Y. Huang, L. Chena, Z. Lia. RSC Adv. 5 2015, 654-664.

79. P. Rong, K. Yang, A. Srivastan, D.O. Kiesewetter, X. Yue, F. Wang, L. Nie, A. Bhirde, Z. Wang, Z. Liu, G. Niu, W. Wang, X. Chen. Theranostics 4 (2014) 229-239.

80. O. Taratula, M. Patel, C. Schumann, M. Analeway, A.J. Pang, H. He. Int. J. Nanomedicine 10 (2015) 2347-2362. 
Chapter 23 